\title{
El renacimiento mediático de la cloroquina y la COVID-19
}

\section{The media renaissance of chloroquine and COVID-19}

\author{
Luis Miguel Tobajas Asensioa \\ a Real Academia de Medicina de Zaragoza, España
}

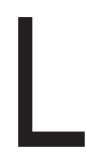

a historia de la cloroquina va ligada al tratamiento del paludismo o malaria desde hace más de 70 años. Se ha utilizado en el tratamiento y profilaxis de paludismo, causada por el protozoo Plasmodium y sus cuatro formas, en regiones endémicas del paludismo. Nuestro premio Nobel, D. Santiago Ramón y Cajal, conoció y padeció los estragos de la malaria en Cuba cuando estuvo de médico militar en esta isla.

La lucha contra el paludismo no está resuelta definitivamente debido a la estrategia de la especie más patógena, Plasmodium "falciparum", de crear resistencias frente al poder terapéutico de la cloroquina.

Es justo reconocer la aportación española al descubrimiento de esa molécula cuyos orígenes nos llevan a 1629 cuando Dña. Francisca Enríquez de Rivera, Condesa de Chinchón y Virreina de Perú, fue curada de malaria con extracto de la corteza de un árbol, "el quino", que era conocido por los nativos indígenas por sus propiedades medicinales.

La búsqueda de investigación de nuevas moléculas antipalúdicas propició la síntesis de la cloroquina en 1934. Esta molécula, descubierta primero en Alemania y luego en Estados Unidos, se utilizó en la Segunda Guerra Mundial como profilaxis de la malaria en los soldados en el norte de África y en el Pacífico. Un dato importante es que esta molécula tiene propiedades moduladoras de la inmunidad y ha hecho posible su utilización en el tratamiento de lupus y la artritis reumatoide.

Esta capacidad inmunomoduladora ha servido para la utilización en el tratamiento de la enfermedad causada por el nuevo coronavirus SARS-CoV-2, más conocida como COVID-19, anunciada por China, en la provincia de Wuhan en diciembre de 2019.

China ha sido pionera en el uso de esta terapia antipalúdica en el tratamiento de esta infección extendida por los cinco continentes y reconocida como pandemia por la Organización Mundial de la Salud el 11 de marzo de 2020. Los primeros trabajos, de autores chinos (Wang et al, 2020 y Yao et al, 2020), informan y recomiendan el uso de la hidroxicloroquina y cloroquina tras unos estudios in vitro en el que comprueba la eficacia contra el SARS-CoV-2.

El grupo de coronavirus pertenece al grupo de virus ARN. Y este virus necesita que el material genético ARN entre en la célula para replicarse. No existe tratamiento específico para esta infección y todos los tratamientos utilizados deben obedecer a interferir la penetración y replicación del virus en las células o a prevenir la respuesta inflamatoria para controlar la infección que puede ocasionar una neumonía mortal causada por el virus.

Un neumólogo e investigador muy prestigioso chino Zhong Nanshan y su equipo afirman, en un artículo de 17 de febrero de la Agencia Oficial de Noticias del Gobierno de la República Popular China, la utilidad del fosfato de cloroquina en el tratamiento de COVID-19 (Xihuanet, 2020). Europa y Estados Unidos, entre otros, acepta esta experiencia sin que exista una evidencia científica contundente. Un tema importante y que pasa desapercibido es que, tanto la cloroquina como la hidroxicloroquina, no solamente son muy baratas, sino que además no necesitan patente.

Europa asume esta posibilidad terapéutica y encuentra en Francia, en el polémico profesor Didier Raoult de Marsella, su principal defensor. Tras un debate científico en Francia, este autor publica un trabajo (Gautret, P. et al, 2020) en el que reitera que la hidroxicloroquina es un tratamiento eficaz en la infección de la COVID-19 en el grupo estudiado. Uno de los puntos débiles de este estudio es precisamente que el número de personas es muy reducido, aunque las autoridades sanitarias francesas avalaron este tratamiento. Esta controversia salta a los medios de comunicación, fundamentalmente a la prensa escrita de todo el mundo, y en algunos casos constatamos el poco rigor científico en algunos medios y la ausencia de las opiniones de los expertos. En nuestra vecina Francia, la polémica llega hasta el presidente Macron, que viaja en persona hasta Marsella para conocer las recomendaciones del Dr. Raoult. 
En España hemos podido comprobar que se han hecho eco los principales diarios de nuestro país en el que, en algunos, la cloroquina se trata como si fuera sustancia milagrosa. El momento cumbre político de esta repercusión mediática se produce cuando el presidente Trump de los Estados Unidos dice que hay un antes y después del tratamiento con este fármaco y que él va a recomendar el tratamiento de cloroquina en su nación para vencer al virus "chino".

Todo ello provoca un desabastecimiento en las farmacias y un acopio preventivo de la cloroquina perjudicando a pacientes que utilizan este fármaco en tratamiento de otras enfermedades como el lupus y el reumatismo inflamatorio. Alemania, Francia y Estados Unidos acaparan las reservas mundiales de esta medicación. España reacciona tarde y, al final, esta medicación la suministra la empresa TEVA (390.000 dosis). España contempla, entre otros, la utilización de cloroquina e hidroxicloroquina en el tratamiento de COVID-19, en la página web de la Agencia Española del Medicamento y Productos Sanitarios (Agencia Española del Medicamento y Productos Sanitarios, 2020).

Actualmente se están realizando más de 400.000 estudios y numerosos ensayos clínicos sobre tratamientos, entre los que se incluyen los antipalúdicos mencionados, y 120 estudios sobre vacunas a nivel mundial. La Organización Mundial de la Salud, en una rueda de prensa de su director general celebrada el día 25 de mayo 2020, anunció la suspensión temporal, de los ensayos clínicos del tratamiento con hidroxicloroquina en pacientes de COVID-19, por precaución debido a su posible toxicidad (Organización Mundial de la Salud [OMS], 2020). Esta polémica continúa con el nuevo anuncio del director general de la OMS, el 3 de junio de 2020, rectificando esta decisión debido a que no hay razón alguna para modificar el protocolo de ensayo, incluida la de la hidroxicloroquina. Nunca se había producido una respuesta científica de estas dimensiones ante una epidemia. Confío, con moderado optimismo, el anuncio de buenas noticias a corto plazo sobre el mejor tratamiento posible de COVID-19, a la espera de la vacuna que proporcione la inmunidad necesaria a nivel mundial en el plazo más breve posible.

En este siglo XXI hay dos temas que generan alarma social y provocan una ansiedad en la población: el cambio climático y las epidemias (Percastre-Mendizabal et al., 2019). Corremos el riesgo de perder nuestra armonía molecular y también social. El mundo tiene miedo. Como dice Carlos López Otín: "Somos vulnerables al virus del miedo" (Mitre, 2020). A este sentimiento humano, debemos responder priorizando la ciencia, la sanidad, la colaboración y la solidaridad, acompañadas de una buena comunicación que nos ayude a vencer, entre todos, esta pandemia.

\section{Referencias bibliográficas}

Agencia Española del Medicamento y Productos Sanitarios. (2020). Recuperado de: https://www. aemps.gob.es

Gautret, P., Lagier, J.C., Parola, P., Hoang, V.T., Meddeb, L., Mailhe, M.,... RaoultD. (2020). Hydroxychloroquine and azitrhromycin as a treatment of COVID-19: results of an open-labed non-randomized clinical trial. International Journal of Antimicrobial Agents. In press. Doi: https://doi.org/10.1016/j. ijantimicag.2020.105949

Mitre, C. (2020, 22 de marzo). El virus del miedo con Carlos López-Otín. Recuperado de https://www. YouTube.com/watch?v=eECxLkMuoEE

Organización Mundial de la Salud. (2020). Recuperado de: https://www.who.int/emergencies/diseases/novelcoronavirus-2019

Percastre-Mendizabal, S., Pont,C., \& Suau-Gomila G.(2019). La gestión comunicativa en redes sociales de la emergencia del Ébola en España. Revista Española de Comunicación en Salud, Supl 1, 80-90.

Wang, M., Cao, R., Zhang, L., Yang, X., Liu, J., Xu, M., ... W, Xiao G. (2020). Redemvisir and chloroquine effectively inhibit recently emerged novel coronavirus (2019-CoV) in vitro. Cell Research, 30, 269-71. Doi: https://doi.org/10.1038/s41422-020-0282-0

Xinhuanet. (2020). Antimalarial drug confirmed effective on COVID-19. Recuperado de: http://www. xinhuanet.com/english/2020-02/17/c_138792545. $\mathrm{htm}$

Yao X., Ye F., Zhang, M., Cui, C. Huang, B., Niu, P.,... Liu, D. (2020). In Vitro Antiviral Activity and Projection of Optimized Dosing Design of Hydroxychloroquine for the Treatment of Severe Acute Respiratory Syndrome Coronavirus2 SARS-CoV-2. Clinical Infectious Diseases, 1-8, in press. 